\title{
PERENCANAAN TEBAL PERKERASAN LENTUR JALAN RAYA KALIBARU - GLENMORE KABUPATEN BANYUWANGI ( PERBANDINGAN METODE BINAMARGA $1987 \&$ 2013)
}

\author{
Muhammad Arif Hidayat ${ }^{1}$, Taufan Abadi $^{2}$, Adhitya Surya Manggala ${ }^{3}$ \\ Program Studi Teknik Sipil, Fakultas Teknik, Universitas Muhammadiyah Jember ${ }^{1}$ \\ J1. Karimata 49, Jember 68121, Indonesia \\ E-mail : luckyrobby8@gmail.com \\ Program Studi Teknik Sipil, Fakultas Teknik, Universitas Muhammadiyah Jember ${ }^{2}$ \\ Jl. Karimata 49, Jember 68121, Indonesia \\ Program Studi Teknik Sipil, Fakultas Teknik, Universitas Muhammadiyah Jember ${ }^{3}$ \\ J1. Karimata 49, Jember 68121, Indonesia
}

\begin{abstract}
Roads are infrastructure that play a very important role in traffic flow, so that during the road service period, efforts are made to avoid problems related to road damage. Road infrastructure which is burdened by high and repetitive traffic volumes will cause a decrease in road quality that can be seen from the condition of the road surface, both structurally and functionally damaged. This study aims to re-plan the thickness of the flexible pavement on the Kalibaru highway - Glenmore Banyuwangi Regency. In this study, to find out how thick the flexible pavement of the Kalibaru - Glenmore highway in Banyuwangi Regency for the next 20 years is in 2038. In this study the authors used the Binamarga Method 1987 and 2013. In this method we have to conduct LHR surveys on these roads and do CBR data retrieval. After the data data is collected, then we can determine the Index of Pavement Thickness of the road. From the calculation results, it is known that the results of the pavement thickness with the Binamarga 1987 method are $4.5 \mathrm{~cm}$ Lapen / Laston, $15 \mathrm{~cm}$ Upper Foundation Layer, $10 \mathrm{~cm}$ Bottom Foundation Layer. Whereas the thickness of road blocks with the method of Binamarga 2013 is WC air conditioner of $4 \mathrm{~cm}, A C B C$ of $13.5 \mathrm{~cm}$, CTB of $15 \mathrm{~cm}$, LPA of Class A of $15 \mathrm{~cm}$.
\end{abstract}

Keywords: infrastructure, traffic flow, flexible pavement, Pavement Thickness

\section{PENDAHULUAN}

Jalan merupakan prasarana yang sangat berperan penting dalam arus lalu lintas, sehingga selama masa layanan jalan tersebut diusahakan menghindari masalah yang berhubungan dengan kerusakan jalan. Prasarana jalan yang terbebani oleh volume lalu lintas yang tinggi dan berulang-ulang akan menyebabkan terjadinya penurunan kualitas jalan yang dapat diketahui dari kondisi permukaan jalan, baik secara struktural maupun fungsional yang mengalami kerusakan. Pada ruas jalan Kalibaru-Genteng merupakan jaringan jalan kolektor (KelasII) yang menghubungkan wilayah Kabupaten Banyuwangi dan sekitarnya. Sebagai salah satu ruas jalan yang menghubungkan Kabupaten dengan intensitas rata-rata kendaraan yang lewat jalan tersebut adalah kendaraan berat. Oleh sebab itu kondisi jalan tersebut akan cepat mengalami kerusakan akibat beban kendaraan. Salah satu cara untuk mengatasi agar tebal perkerasan tidak mudah mengalami kerusakan dan dapat digunakan dalam jangka waktu yang relatif lama, maka diperlukan adanya evaluasi dan perencanaan tebal perkerasan jalan rayanya.

Berdasarkan latar belakang tersebut, maka rumusan masalah sebagai berikut :

1. Bagaimana tingkat kinerja dengan perhitungan jumlah volume lalu lintas, kapasitas dan derajat kejenuhan pada ruas jalan Kalibaru-Genteng Kabupaten Banyuwangi ?

2. Berapa perencanaan tebal perkerasan yang di butuhkan untuk 20 tahun yang akan 
datang pada ruas jalan Kalibaru-Genteng Kabupaten Banyuwangi?

3. Bagaimana hasil perbandingan dari perhitungan tebal perkerasan menggunakan metode binamarga 1987 dan 2013 ?

4. Bagaimana hasil perbandingan dari perhitungan tebal perkerasan menggunakan metode binamarga 1987 dan 2013 dengan tebal perkerasan eksisting di lapangan?

Penelitian ini bertujuan untuk membandingkan nilai tebal perkerasan mengunakan metode Bina Marga 1987 dan 2013.

\section{METODE PENELITIAN}

\section{START}

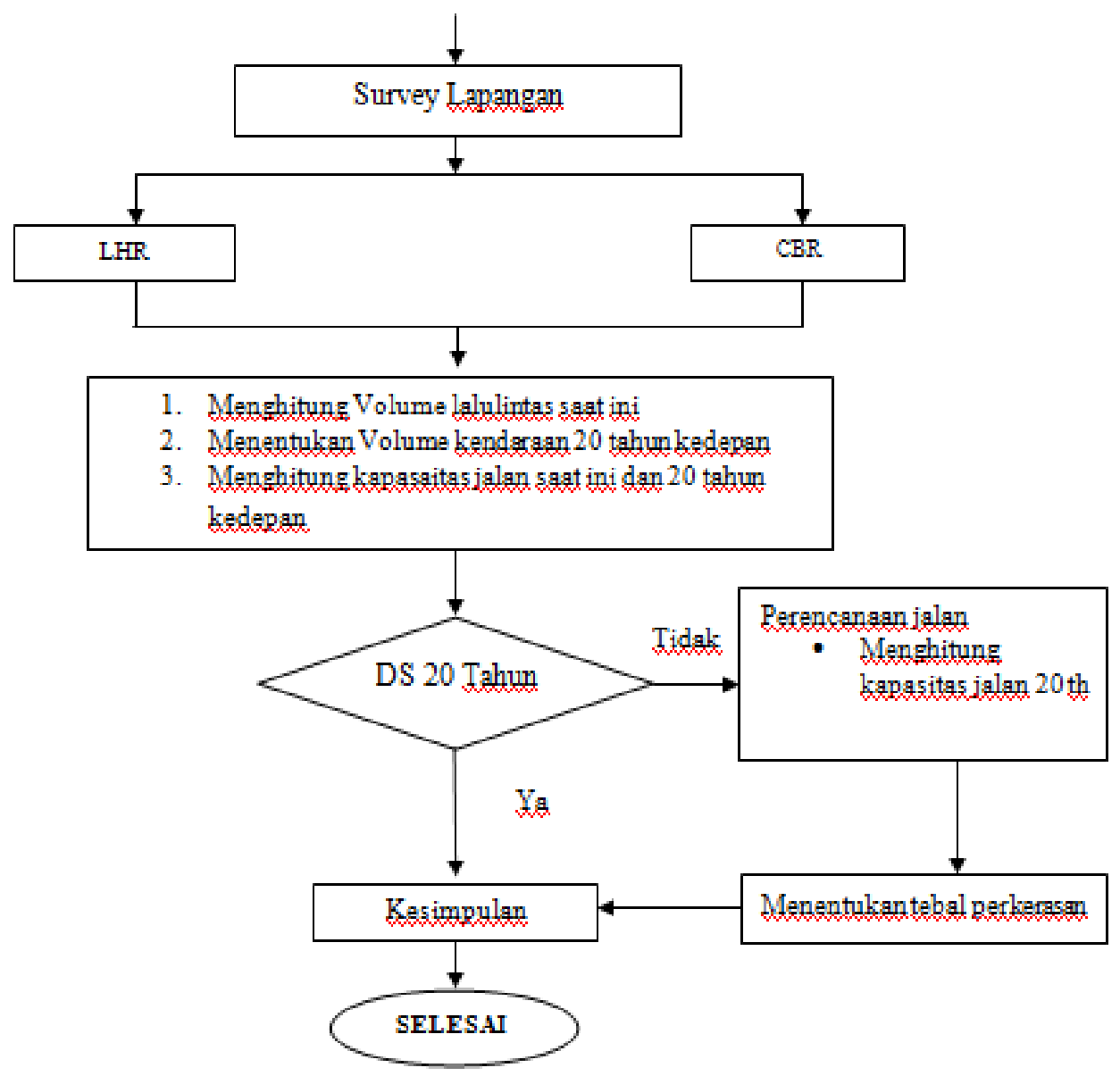

Gambar 1 Bagan Alur Penelitian

\section{Pengumpulan Data Penelitihan.}

Data yang harus dikumpulkan dalam studi ini marupakan data primer, yang meliputi data volume lalu lintas, serta data skunder.

\section{Data Primer}

Data yang diperoleh atau dikumpulkan langsung dari lokasi penelitihan. Data primer yang dibutuhkan antara lain : volume lalu lintas,dan kondisi jalan saat ini uas jalan pakusari - silo kabupaten jember.

a. Volume lalu lintas

Pada Volume Lalu lintas ini dapat dinyatakan dalam satuan kendaran/jam atau smp/menit. Survey ini dimaksudkan untuk mengumpulkan data volume lalu lintas perjam serta klasifikasi 
kendaraan. Pengamatan dilakukan selama 2 kali.

\section{Data Sekunder}

Yaitu berasal dari intasi pemerintahan yang menangani perencanaan jalan maupun intansi lain yang memiliki dokumendokumen yang dibutuhkan dalam perencanaan. Data sekunder yang diperlukan antara lain :

a. Data - data perencanaan jalan yang didapat dari Dinas Bina Marga.

b. Data Penduduk

\section{HASIL DAN PEMBAHASAN}

\section{Data hasil survey lalu lintas harian}

data volume kendaraan harian (LHR) di dapat dari pengamatan langsung selama 24 jam yg dimulai pada oktober tanggal 15-16 2018 pada hari rabu-kamis jam 06-00 s/d 0600 WIB di pakusari-silo depan balai desa kejayan, dari hasil pengamatan di peroleh data sebagai berikut:

Tabel 1 Lalu lintas harian

\begin{tabular}{|c|l|c|c|c|}
\hline No & \multicolumn{1}{|c|}{ Jenis Kendaraan } & \multicolumn{2}{|c|}{ Arah (Kendaraan/Hari) } & \multirow{2}{*}{ Jumlah } \\
\cline { 3 - 4 } & Sember & Banyuwangi & \\
\hline 2 & $\begin{array}{c}\text { Sepeda Motor,roda 3,vespa } \\
\text { pribadi,pick up,mobil } \\
\text { box,mobil hantaran. }\end{array}$ & 3332 & 3298 & 6630 \\
\hline 3 & Bus & 754 & 736 & 1490 \\
\hline 4 & Truck 2 as & 905 & 922 & 1827 \\
\hline 5 & Truck 3 as & 463 & 454 & 917 \\
\hline 6 & $\begin{array}{l}\text { Truck } \\
\text { Gandengan,semi/trailer }\end{array}$ & 252 & 251 & 503 \\
\hline 7 & Kendaraan tak bermotor & 82 & 61 & 143 \\
\hline Jumlah & & $\mathbf{7 7 0 5}$ & $\mathbf{7 6 5 2}$ & $\mathbf{1 5 3 5 7}$ \\
\hline
\end{tabular}

\section{Perhitungan derajat kejunuhan (DS)}

Derajat kejenuhan didefinisikan sebagai rasio arus dan kapasitas, digunakan sebagai faktor kunci dalam penentuan perilaku lalu lintas pada satu segmen jalan. Nilai derajat kejenuhan menunjukan segmen jalan mempunyai masalah atau tidak. DS dapat dihitung dengan rumus:

$\mathbf{D S}=\mathbf{Q} / \mathbf{C}$

Dengan :

Ds $=$ derajat kejenuhan

$\mathrm{Q}=$ Volume lalu lintas

$\mathrm{C}=$ Kapasitas
Maka kapasitas jalan:

$\mathrm{C}=\mathrm{C} 0 \mathrm{x}$ fcw $\mathrm{x}$ fcsp $\mathrm{x}$ fcsf $\mathrm{x}$ fces

\section{Co,fcw,fcsp,fesf,fces}

di dapat dari tabel:

Tabel 2 kapasitas dasar (CO)

\begin{tabular}{|c|c|c|}
\hline \multirow{2}{*}{ NO } & $\begin{array}{c}\text { Tipe jalan/Tipe } \\
\text { alinyemen }\end{array}$ & \multirow{2}{*}{$\begin{array}{c}\text { Kapasitas dasar } \\
\text { Total kedua arah } \\
\text { (smp/jam })\end{array}$} \\
\hline 1 & Dua-lajur tak- & 3100 \\
\hline 2 & Datar & 3000 \\
\hline 3 & Bukit & 2900 \\
\hline
\end{tabular}

Tabel 3 Penyesuaian Kapasitas untuk Pengaruh Lebar Jalur Lalu-lintas untuk Jalan luar kota $\left(\mathrm{FC}_{\mathrm{W}}\right)$

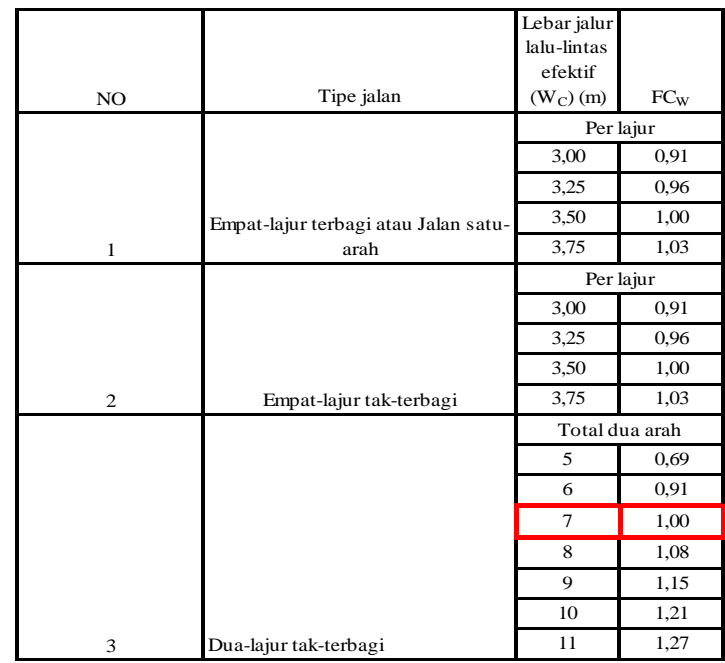

Tabel 4 Faktor Penyesuaian Kapasitas Untuk Pemisahan

Arah

(FCsp)

\begin{tabular}{|c|c|c|c|c|c|c|c|}
\hline No & Pemisah Arah SP \% - \% & & $50-50$ & $55-45$ & $60-40$ & $65-35$ & $770-30$ \\
\hline 1 & & \begin{tabular}{|c|} 
Dua-haju \\
22
\end{tabular} & 1,00 & 0.97 & 0,4 & 0,91 & \begin{tabular}{|l|l|}
0,88 \\
\end{tabular} \\
\hline 2 & $\mathrm{FC}_{S \mathrm{P}}$ & \begin{tabular}{|l|} 
Empat- \\
Giju 42
\end{tabular} & 1,00 & 0,975 & 0,95 & 0.925 & $0,0,0$ \\
\hline
\end{tabular}

Tabel 5 Faktor Penyesuaian kapasitas untuk pengaruh hambatan samping dan lebar bahu efektif (FCsf)

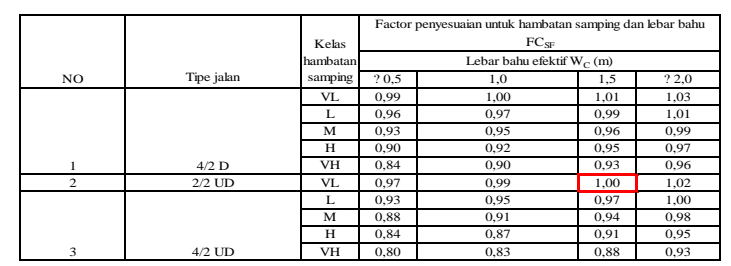

Tabel 6 Faktor Penyesuaian Kapasitas untuk Ukuran Kota (FCCS) 


\begin{tabular}{|c|c|c|}
\hline NO & $\begin{array}{c}\text { Ukuran kota (Juta } \\
\text { penduduk) }\end{array}$ & $\begin{array}{c}\text { Factor penyesuaian } \\
\text { untuk ukuran kota }\end{array}$ \\
\hline 1 & $<0,1$ & 0,86 \\
\hline 2 & $0,1-0,5$ & 0,90 \\
\hline 3 & $0,5-1,0$ & 0,94 \\
\hline 4 & $1,0-3,0$ & 1,00 \\
\hline 5 & $>3,0$ & 1,04 \\
\hline
\end{tabular}

Dari tabel di atas didapatkan nilai FCcs adalah 1,00 di karenakan jumlah penduduk di banyuwangi adalah sekitar 1,6 juta.

Maka nilai $\mathrm{C}$ adalah :

$\mathrm{C}=3100 \times 1,00 \times 1,00 \times 1.00 \times 1.00$

$\mathrm{C}=3100 \mathrm{smp} / \mathrm{jam}$

Dengan jumlah kendaraan hasil pengamatan langsung tahun $2018=639.875 \mathrm{smp} / \mathrm{jam}$ dan lama pengamatan 24 jam,

maka Qsmp :

Tabel 7 Tabel Perhitungan Qsmp tahun 2018

\begin{tabular}{|c|l|r|r|r|}
\hline No & Jenis Kendaraan & $\begin{array}{c}\text { LHR 2018 } \\
\text { (JumlahJam) }\end{array}$ & emp MKJ 97 & Qsmp \\
\hline 1 & Sepeda motor, roda 3, & 276.25 & 0.25 & 69.0625 \\
\hline 2 & Kendaraan ringan, mob & 167.25 & 1 & 167.25 \\
\hline 3 & Bus & 62.083333 & 1.2 & 74.5 \\
\hline 4 & Truk 2 as & 76.125 & 1.2 & 91.35 \\
\hline 5 & Truk 3 as & 38.208333 & 1.2 & 45.85 \\
\hline 6 & Truk Gandengan & 14 & 1.2 & 16.8 \\
\hline 7 & semitralertrailer & 6.9583333 & 1.2 & 8.35 \\
\hline 8 & Kendaraan tak bermotd & 5.9583333 & 0.85 & 5.06458 \\
\hline \multicolumn{4}{|r}{ Jumlah } \\
\hline
\end{tabular}

Hasil perhitungan $\mathrm{C}$ smp/jam $=3100 \mathrm{smp} / \mathrm{jam}$ dan Qsmp = $241.915 \mathrm{smp} / \mathrm{kendaraan} / \mathrm{jam}$, Sehingga didapat DS, sebagai berikut :

$\mathrm{DS} \quad=\mathrm{Qsmp} / \mathrm{C}=241.915 / 3100$

$=0.078036962 \mathrm{smp} / \mathrm{kendaraan} / \mathrm{jam}$

(A)

Tabel 8 Tingkat pelayanan 2018

\begin{tabular}{|c|c|c|c|}
\hline No & Tingkat Pelayanan & Kriteria & Nilai \\
\hline 1 & s. & \begin{tabular}{|l|} 
Kondisi arus dengan \\
kecepatan tinggi dan \\
volume lalulintas \\
rendah. Pengemudi \\
dapat meilih kecepatan \\
yang di inginkan
\end{tabular} & $0.00-0.19$ \\
\hline 2 & в & \begin{tabular}{|l|} 
Dalam zone harus stabiil. \\
Pengemendi memiliki \\
kebebasan yang cukup \\
untuk memilih \\
kecepatannya
\end{tabular} & $0.20-0.44$ \\
\hline 3 & c & \begin{tabular}{|l|} 
Dalam zone arus stabil \\
pengemudididibatasi \\
dalam memilih \\
kecepatannzya
\end{tabular} & $0.45-0.74$ \\
\hline 4 & D & \begin{tabular}{|l|} 
Mendekatitiarus tidak \\
stabil dimana hampir \\
selumah pengemudi \\
akan dibatasi volume \\
pelayanan berkaitan \\
dengan aktifitas yang \\
dapat ditolerir (diterima)
\end{tabular} & $0.75-0.84$ \\
\hline 5 & E & \begin{tabular}{|l} 
Volume arus lalu-lintas \\
mendekati atau berada \\
pada kapasitas. Arus \\
adalah tidak stabil \\
dengan kondisi yang \\
sering berhenti \\
\end{tabular} & $0.85-1.0$ \\
\hline 6 & $\mathrm{~F}$ & \begin{tabular}{|l} 
Arus yang sering \\
dipaksakan atau macet \\
pada kecepatan \\
kecepatan yang rendah. \\
Antrian yang panjang \\
dan terjadi hambatan- \\
hambatan yang besar
\end{tabular} & Lebih besar dari 1.0 \\
\hline
\end{tabular}

Dari tabel di atas kita dapatkan tingkat pelayanan jalan Kalibaru-Glenmore Kabupaten Banyuwangi pada tahun 2018 yaitu A.
Sedangkan untuk DS tahun 2038 :

Tabel 9 Tabel perhitungan Qsmp 2038

\begin{tabular}{|c|c|c|c|c|}
\hline No & Jenis Kendaraan & $\begin{array}{c}\text { LHR 2018 } \\
\text { (Kendaraan/Jam) }\end{array}$ & $\begin{array}{c}\mathrm{i}=5 \% \\
\mathrm{Qn}=\mathrm{Q} 0(1+\mathrm{i})^{\wedge} \mathrm{N}\end{array}$ & \begin{tabular}{|l|} 
Qsmp \\
2038
\end{tabular} \\
\hline 1 & $\begin{array}{l}\begin{array}{l}\text { Sepeda motor, roda 3, } \\
\text { vespa }\end{array} \\
\end{array}$ & 276.25 & 2.653 & 732.974 \\
\hline 2 & $\begin{array}{l}\text { Kendaraan ringan, } \\
\text { mobil pribadi, pick } \\
\text { up,mobil box, mobil } \\
\text { hantaran. } \\
\end{array}$ & 167.25 & 2.653 & 443.764 \\
\hline 3 & Bus & 62.083333 & 2.653 & 164.726 \\
\hline 4 & Truk 2 as & 76.125 & 2.653 & 201.982 \\
\hline 5 & Truk 3 as & 38.208333 & 2.653 & 101.378 \\
\hline 6 & $\begin{array}{l}\text { Truk Gandengan, } \\
\text { semi/trailer }\end{array}$ & 14 & 2.653 & 37.1462 \\
\hline 7 & semi trailer/trailer & 6.9583333 & 2.653 & 18.4625 \\
\hline 8 & $\begin{array}{l}\begin{array}{l}\text { Kendaraan tak } \\
\text { bermotor }\end{array} \\
\end{array}$ & 5.9583333 & 2.653 & 15.8092 \\
\hline \multicolumn{4}{|c|}{ Jumlah } & 1716. \\
\hline
\end{tabular}

Hasil perhitungan $\mathrm{C}$ smp/jam $=3100 \mathrm{smp} / \mathrm{jam}$ dan Qsmp $=1716.24 \mathrm{smp} / \mathrm{kendaraan} / \mathrm{jam}$, Sehingga didapat DS, sebagai berikut :

DS $=$ Qsmp $/ \mathrm{C}=1716.241 / 3100$

(C)

$$
=0.553626258 \mathrm{smp} / \mathrm{kendaraan} / \mathrm{jam}
$$

Tabel 10 Tingkat pelayanan 2038

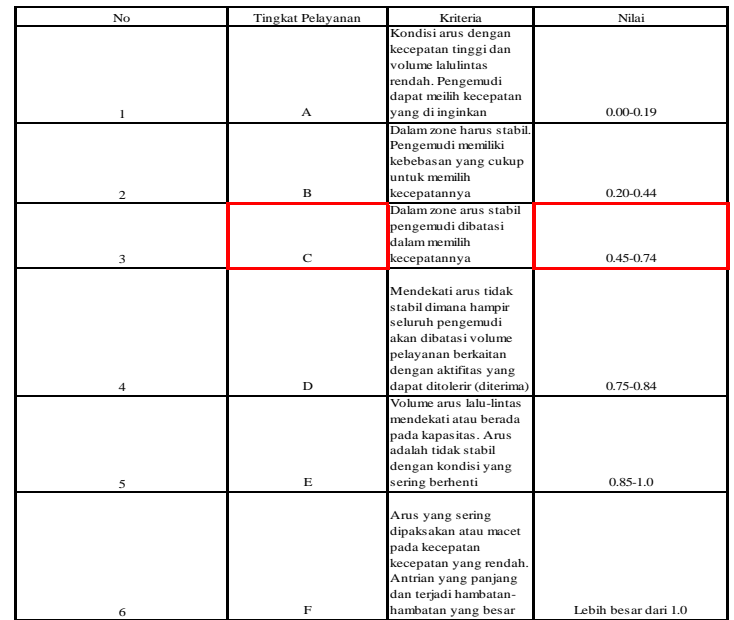

Dari tabel di atas didapatkan tingkat pelayanan jalan Kalibaru-Glenmore Kabupaten Banyuwangi pada tahun 2038 adalah C.

Angka Ekivalen (E), dari masing-masing kendaraan

Tabel 11 Angka ekivalen E

\begin{tabular}{|c|l|c|}
\hline NO & Jenis Kendaraan & Angka Ekivalen ( E) \\
\hline 1 & Mobil Penumpang & 0,0004 \\
\hline 2 & Bus & 0,1876 \\
\hline 3 & & \\
\hline 4 & Truck 2 Sumbu Ringan & 1.3084 \\
\hline 5 & Truck 3 Sumbu & 12,290 \\
\hline 6 & Truck Gandeng & 14,186 \\
\hline & Semi trailer/traler & 13.859 \\
\hline
\end{tabular}




\section{Lintas Ekivalen Permulaan (LEP)}

Tabel 12 Nilai Lintas Ekivalen Permulaan

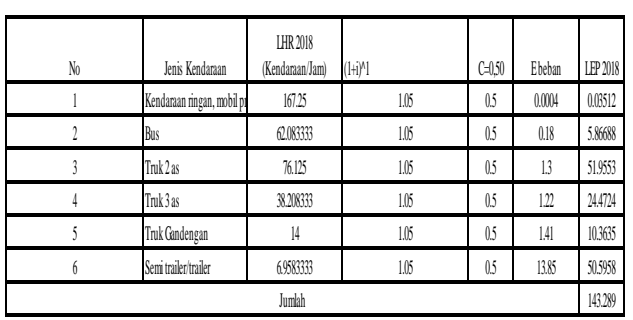

Jadi jumlah LEP yang di dapatkan dari hitungan tabel di atas adalah sebesar 143.289.

\section{Lintas Ekivalen Akhir ( LEA )}

Tabel 13 Nillai Lintas Ekivalen Akhir

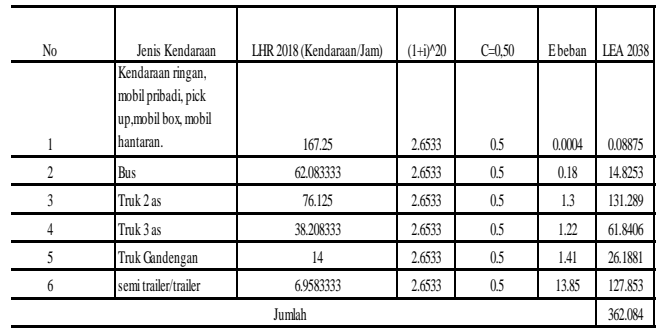

Jadi jumlah LEA yang di dapatkan dari hitungan tabel di atas adalah sebesar 362.084.

\section{Lintas Ekivalen Tengah (LET)}

Dari hasil analisa menggunakan microsoft excel di dapatkan nilai lintas ekivalen tengah (LET) sebagai berikut :

$$
\begin{aligned}
\text { LET } & =1 / 2(L E P+L E A) \\
& =1 / 2(143.289+362.084) \\
& =252.686
\end{aligned}
$$

Jadi jumlah LET yang di dapatkan dari hitungan di atas adalah sebesar 362.084.

\section{Lintas Ekivalen Rencana (LER)}

Dari hasil analisa menggunakan microsoft excel di dapatkan nilai lintas ekivalen rencana (LER) sebagai berikut :

$$
\begin{aligned}
\text { LER } & =\text { LET } \times \text { UR } / 10 \\
& =252.686 \times 20 / 10 \\
& =505.373
\end{aligned}
$$

Jadi jumlah LER yang di dapatkan dari hitungan di atas adalah sebesar 505.373.

\section{Daya Dukung Tanah Dasar (DDT)}

Pada kekuatan konstruksi perkerasan jalan sangat tergantung dari sifat - sifat dan daya dukung tanah (DDT) dasar. Dari bermacam macam cara pengerjaan untuk menentukan kekuatan tanah dasar, yang umum dipakai adalah cara CBR (California Bearing Ratio). CBR adalah perbandingan antara beban penetrasi suatu bahan terhadap bahan standar dengan kedalaman dan kecepatan penetrasi yang sama.Daya dukung tanah ditentukan berdasarkan grafik korelasi antara nilai CBR tanah dasar $=55.21 \%$ (Sumber Bina Marga, 2012). Grafik nilai korelasi CBR dan DDT dapat dilihat pada Gambar dibawah ini :

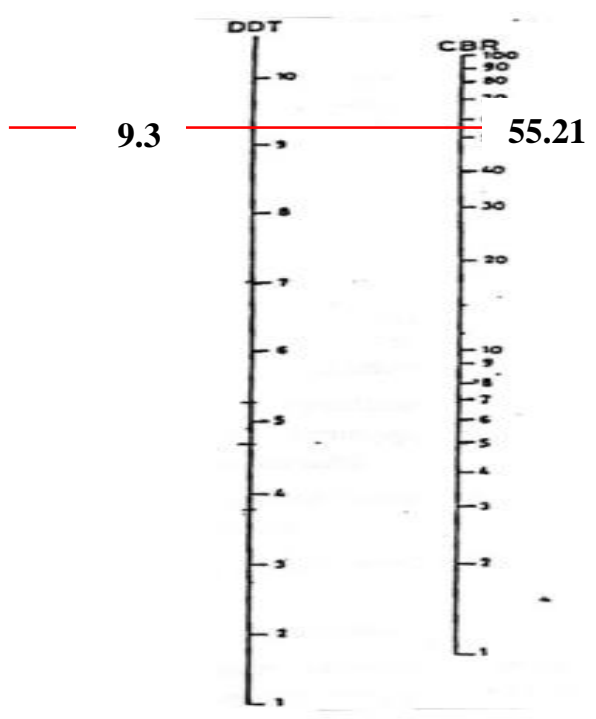

Gambar 2 Nilai korelasi data CBR dan DDT.

Perhitungan berikutnya dengan memperhatikan Nomogram Indeks Tebal Perkerasan (ITP), di bawah ini.

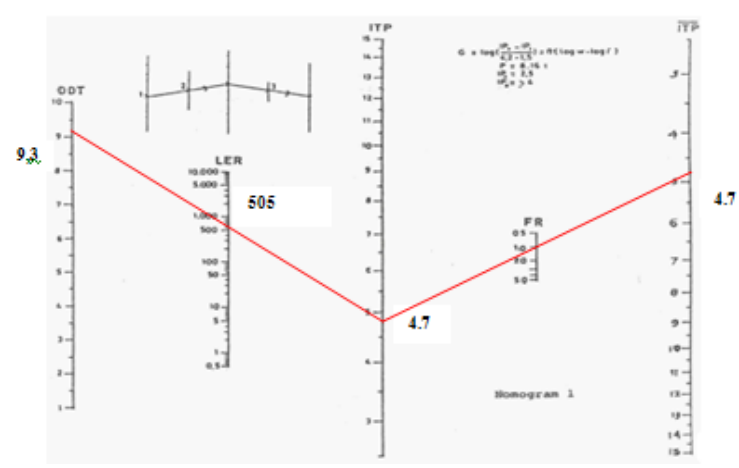

Gambar 3 nomogram ITP 


\section{Penentuan indek tebal perkerasan Bina Marga 1987}

Pada Indeks Tebal lapisan perkerasan dinyatakan dengan rumus, sebagai berikut :

$\mathrm{ITP}=\mathrm{a} 1 . \mathrm{D} 1+\mathrm{a} 2 . \mathrm{D} 2+\mathrm{a} 3 \cdot \mathrm{D} 3$

Perhitungannya sebagai berikut :

$\mathrm{ITP}=\mathrm{a} 1 \mathrm{D} 1+\mathrm{a} 2 \mathrm{D} 2+\mathrm{a} 3 \mathrm{D} 3$

$4.7=(0.35 \times \mathrm{xD} 1)+(0.12 \times 15)+(0.12 \times 10)$

$4.7=(0.35 \mathrm{D} 1)+1.8+1.20$

$\mathrm{D} 1=4.7-3.00 / 0.35$

$\mathrm{D} 1=4,85 \mathrm{Cm}$

D1 $=5 \mathrm{Cm}$ (di sesuaikan mengikuti Tabel

Batas Minimum Tebal Lapisan Permukaan)
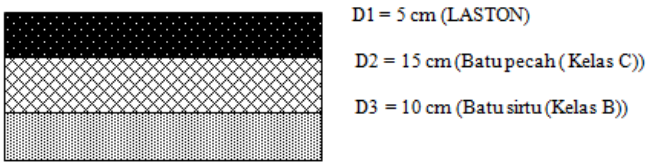

\section{Perhitungan Perkerasan Bina Marga 2013}

Perhitungan perkerasan lentur dengan metode Bina Marga 2013, langkah-langkahnya sebagai berikut :

a. Penetapan Umur Rencana (UR)

b. Klasifikasi Kendaraan dan Nilai VDF standar

c. Menentukan Faktor pertumbuhan lalu lintas (i)

d. Menghitung Faktor pertumbumhan lalu lintas sesuai umur rencana $(\mathrm{R})$

e. Menentukan Nilai Multi Traffic Multiplier (TM)

f. Menentukan Faktor Distribusi Lajur (DL)

g. Menghitung Beban Sumbu Standar Kumulatif

h. Pemilihan Jenis Perkerasan

i. Solusi Desain 2 Pondasi Jalan minimum

j. Desain perkerasan lentur opsi biaya minimum

\section{Penetapan Umur Rencana $($ UR $)=20$ tahun}

Umur Rencana $=20$ tahun (direncanakan), dimana pada Manual
Perkerasan jalan No.02/M/BM/2013 halaman 9, yaitu Lapisan lentur berbutir dan CBT.

Tabel 14 umur rencana

\begin{tabular}{|c|c|c|c|}
\hline No & $\begin{array}{c}\text { Lapisan } \\
\text { Perkerasan }\end{array}$ & Elemen Perkerasan & $\begin{array}{c}\text { Umur Rencana } \\
\text { (Tahun) }\end{array}$ \\
\hline \multirow{6}{*}{1} & \multirow{6}{*}{$\begin{array}{c}\text { Perkerasan } \\
\text { Lentur }\end{array}$} & $\begin{array}{c}\text { Lapisan atas dan } \\
\text { lapisan berbutir dan } \\
\text { CBT }\end{array}$ & 20 \\
\hline & & Pondasi jalan & \multirow{6}{*}{40} \\
\hline & & $\begin{array}{c}\text { Semua lapisan jalan } \\
\text { untuk area yang }\end{array}$ & \\
\hline & & $\begin{array}{l}\text { tidak diijinkan } \\
\text { sering ditinggikan } \\
\text { akibat pelapisan }\end{array}$ & \\
\hline & & $\begin{array}{c}\text { ulang, missal : jalan } \\
\text { perkotaan, } \\
\text { underpass, } \\
\text { jembatan, } \\
\text { torowongan }\end{array}$ & \\
\hline & & $\begin{array}{c}\text { Cement Treateed } \\
\text { Based }\end{array}$ & \\
\hline 2 & Perkerasankaku & $\begin{array}{c}\text { Lapis pondasi atas, } \\
\text { lapis pondasi } \\
\text { bawah, lapis } \\
\text { pondasi semen dan } \\
\text { pondasi jalan }\end{array}$ & \\
\hline 3 & $\begin{array}{l}\text { Jalan Tanpa } \\
\text { Penutup }\end{array}$ & Semen elemen & Minimum 10 \\
\hline
\end{tabular}

Klasifikasi Kendaraan dan Nilai VDF4 standar

Tabel 15 Nilai VDF4 standar

\begin{tabular}{|c|l|c|}
\hline No & \multicolumn{1}{|c|}{ Jenis Kendaraan } & VDF4 \\
\hline 1 & Motor & 0 \\
\hline 2 & Mobil & 0 \\
\hline 3 & Bus & 1 \\
\hline 4 & Truk sumbu2 as & 0.8 \\
\hline 5 & Truk sumbu 3 as & 7,6 \\
\hline 6 & Truk berat (Gandengan) Trailer & 36,9 \\
\hline
\end{tabular}

Tabel 16 Pertumbuhan lalu lintas

\begin{tabular}{|c|c|c|c|}
\hline No & Tipe Jalan & $2011-2020$ & $>2021-2030$ \\
\hline 1 & $\begin{array}{c}\text { Arteri dan } \\
\text { Perkotaan(\%) }\end{array}$ & 5 & 4 \\
\hline 2 & $\begin{array}{c}\text { Kolektor rurel } \\
(\%)\end{array}$ & 3,5 & 2,5 \\
\hline 3 & $\begin{array}{c}\text { Jalan Desa } \\
(\%)\end{array}$ & 1 & 1 \\
\hline
\end{tabular}

\section{Faktor Pertumbuhan Lalu Lintas Sesuai Umur Rencana}

Untuk menghitung faktor pertumbuhan lalu lintas sesuai umur rencana (R) dihitung sebagai berikut :

$$
\begin{aligned}
\mathrm{i} & =0.05(5 \%) \\
\mathrm{UR} & =20 \text { Tahun } \\
\mathrm{R} & =(1+0.01 \mathrm{i})^{\wedge} \mathrm{UR}-1 /(0.01 \mathrm{i}) \\
& =0.01005 / 0.0005 \\
& =20.0953
\end{aligned}
$$

\section{Traffic multiplier (TM)}

Traffic multiplier (TM) digunakan untuk mengoreksi ESA4 akibat kelelahan lapisan aspal. Menurut pdf manual desain perkerasan jalan raya no 2 binamarga 2013 hal.36, Nilai 
TM kelelahan lapisan aspal (TM lapisan aspal) untuk kondisi pembebanan yang berlebih di Indonesia adalah berkisar 1,8 - 2 maka kita akan ambil rata ratanya yaitu 1,9 .

\section{Nilai Distribusi Lajur (DL)}

Nilai Distribusi Lajur di tentukan oleh tabel Faktor Distribusi lajur yaitu sebagai berikut :

Tabel 17 Faktor Distribusi Lajur

\begin{tabular}{|c|c|c|}
\hline No & $\begin{array}{c}\text { Jumlah lajur } \\
\text { setiap arah }\end{array}$ & $\begin{array}{c}\text { Kendaraan Niaga pada lajur } \\
\text { desain (\% terhadap populasi } \\
\text { kendaraan niaga) }\end{array}$ \\
\hline 1 & 1 & 100 \\
\hline 2 & 2 & 80 \\
\hline 3 & 3 & 60 \\
\hline 4 & 4 & 50 \\
\hline
\end{tabular}

Dari tabel didapatkan nilai DL nya adalah 80 dikarenakan jumlah jalur setiap arah pada lokasi penelitian adalah 2 .

\section{Menghitung Beban Sumbu Standar Kumulatif}

Tabel 18 Perhitungan Beban Sumbu Standar Kumulatif

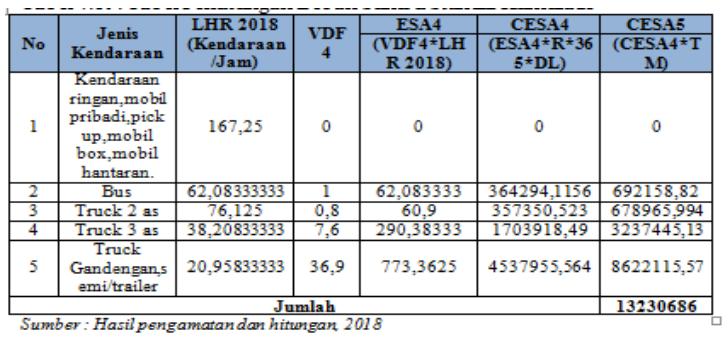

\section{Solusi Desain Pondasi Jalan minimum}

Solusi desain pondasi jalan minimum dapat diliat pada tabel 4.20, Solusi desain pondasi jalan minimum di sesuaikan pada besar CBR Tanah Dasar pada lokasi yang akan di desain tebal perkerasan lentur jalan rayanya

Tabel 19 Solusi desain 2 pondasi

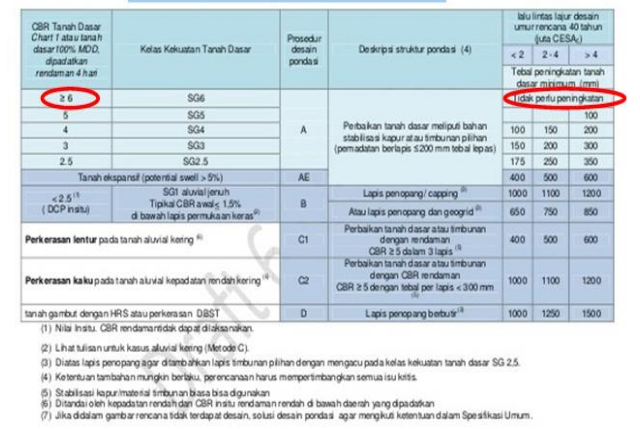

Dikarenakan nilai CBR lebih dari 6 maka tidak perlu ada peningkatan

\section{Desain Perkerasan Lentur Opsi Biaya Minimum}

Untuk menentukan tebal perkerasan lentur pada metode binamarga 2013 dapat menggunakan tabel perkerasan lentur opsi biaya minimum dapat diliat pada tabel dibawah ini:

Tabel 20 Desain perkerasan lentur opsi biaya minimum

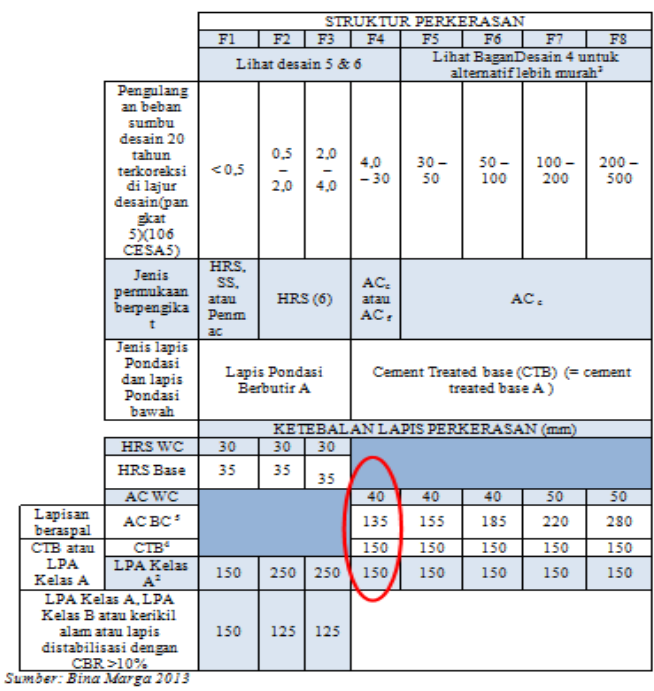

Dikarenakan jumblah hasil perhitungan pada CESA5 adalah 13230686 atau 13,23 x 105 maka perkerasan yang di dapatkan adalah sebagai berikut :
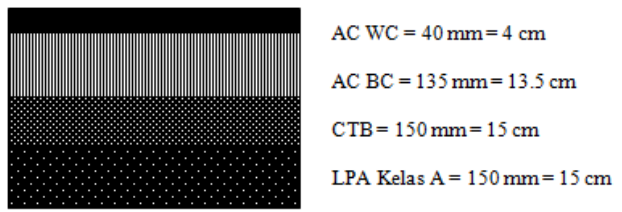

Gambar 4 lapisan tebal perkerasan 2013

\section{Kesimpulan dan Saran}

kesimpulan dalam penelitian ini adalah sebagai berikut :

1. Kondisi kinerja pada ruas jalan raya Kalibaru - Glenmore Kabupaten Banyuwangi berdasarkan survey tanggal 22-23 Oktober 2018 di dapat volume lalu-lintas tahun $2018=$ 241.915 kendaraan/jam, didapat $\mathrm{DS}=$ $0.078037 \mathrm{smp} / \mathrm{kendaraan} / \mathrm{jam}$ dengan tingkat pelayanan (A) yaitu kondisi arus dengan kecepatan tinggi dan volume lalu-lintas rendah. Pengemudi dapat memilih kecepatan 
yang diinginkannya tanpa hambatan. Sedangkan untuk peramalan kondisi lalu-lintas dengan asumsi $\mathrm{i}=5 \%$ maka didapat $\mathrm{Q}=$ 1716.241 kendaraan/jam dengan DS tahun 2038 yaitu 0.553626 dengan tingkat pelayanan (C) adalah dalam zone arus stabil pengemudi dibatasi dalam memilih kecepatan.

2. Untuk perhitungan tebal perkerasan lentur metode Bina Marga 1987 dengan nilai $\mathrm{CBR}=55,21 \%$ (Sub Grade) dan nilai ITP $=4,7$. Hasil perencanaan tebal perkerasan lentur dengan metode Bina Marga 1978 di dapat : LASTON $=5 \mathrm{~cm}$, Lapisan Pondasi Atas (Batu pecah CBR $\min .35 \%)=15 \mathrm{~cm}$, Lapisan pondasi Bawah (Batu sirtu CBR min.65\%) = $10 \mathrm{~cm}$. Untuk hasil perhitungan dengan Metode Bina Marga 2013, didapat : AC WC = $4 \mathrm{~cm}, \mathrm{AC} B C=13,5 \mathrm{~cm}, \mathrm{CTB}=15 \mathrm{~cm}, \mathrm{LPA}$ Kelas A $($ CBR $\min .90 \%)=15 \mathrm{~cm}$.

3. Hasil perhitungan tebal perkerasan lentur kedua metode tersebut yaitu : Binamarga 1987 $=30 \mathrm{~cm}$, Binamarga $2013=47,5 \mathrm{~cm}$. Selisih tebal perkerasan setebal $17,5 \mathrm{~cm}$ ( lebih tebal metode Bina Marga 2013).

4. Dari hasil survey didapatkan tebal eksisting dilapangan $25 \mathrm{~cm}$. Kemudian hasil perhitungan menunjukan pebandingan ke dua metode tersebut dengan tebal eksisting di lapangan yaitu sebagai berikut : Binamarga $1987=5 \mathrm{~cm}$, Binamarga $2013=22,5 \mathrm{~cm}$.

\section{Saran}

Saran dalam penelitian ini adalah berikut :

1. Perlu adanya perhitungan ulang pada tebal perkerasan baik dengan metode Bina Marga tahun 1987 atau 2013. Hal ini dikarnakan kendaraan yang melewati jalur tersebut terdapat kendaraan berat (Jawa-Bali).

2. Untuk peneliti selanjutnya di harapkan dapat membandingkan perbandingan eksisting tebal perkerasan dilapangan dan tebal perencanakan yang di rencanakan dengan lebih detail.

3. Perlunya penegakan peraturan untuk beban angkutan (tonase) pada kendaraan berat pada jalan raya Kalibaru - Glenmore Kabupaten.

\section{REFRENSI}

Alamsyah , Ansyori A, Ir.MT. 2001. Rekayasa Jalan Raya. Malang : UMM Press

Departemen Pekerjaan Umum. 1987. Petunjuk Perencanaan Tebal Perkiraan Lentur Jalan Raya. Jakarta : Binamarga

Departemen Pekerjaan Umum. 2013. Manual Desain Perkerasan Jalan. Jakarta : Binamarga

Sukirman S. 2010. Perencanaan Tebal Perkiraan Lentur. Bandung : Nova Bandung 